\title{
Examining the Thermal Stability of an Al-Mg-Sc Alloy Processed by High-Pressure Torsion
}

\author{
Pedro Henrique R. Pereira ${ }^{a, b *}$, Yi Huang ${ }^{a}$, Terence G. Langdon ${ }^{a}$ \\ ${ }^{a}$ Materials Research Group, Faculty of Engineering and the Environment, University of Southampton, \\ SO17 1BJ, Southampton, U.K. \\ ${ }^{b}$ CAPES Foundation, Ministry of Education of Brazil, DF 70040-020, Brasilia, DF, Brazil
}

Received: February 20, 2017; Revised: July 30, 2017; Accepted: September 19, 2017

\begin{abstract}
An $\mathrm{Al}-3 \% \mathrm{Mg}-0.2 \% \mathrm{Sc}$ alloy was solution treated and subjected to 10 turns of high-pressure torsion (HPT). Thereafter, the HPT-processed material was annealed for 1 hour at temperatures ranging from 423 to $773 \mathrm{~K}$ and its mechanical properties and microstructural evolution were examined using microhardness measurements and EBSD analysis. The results demonstrate that the Al-Mg-Sc alloy exhibits an average microhardness of $\sim 190 \mathrm{Hv}$ and an average grain size of $\sim 140 \mathrm{~nm}$ immediately after HPT processing and also after further annealing at $423 \mathrm{~K}$. Conversely, it is shown that annealing at temperatures above $473 \mathrm{~K}$ leads to a substantial decrease in the hardness values as well as a sharp increase in the grain size of the material previously processed by HPT. In addition, detailed EBSD analysis revealed the formation of a bi-modal distribution of grains after annealing at temperatures from 623 to $773 \mathrm{~K}$, and this becomes more uniform with increasing temperatures.
\end{abstract}

Keywords: Aluminium alloys, Hall-Petch relationship, Hardness, High-pressure torsion, Severe plastic deformation, Thermal stability

\section{Introduction}

The growing interest for more fuel-efficient vehicles has motivated the development of $\mathrm{Al}$ alloys with high strength to density ratio, especially designed for applications in the automotive and aerospace industries ${ }^{1,2}$. Severe plastic deformation (SPD) $)^{3,4}$ techniques have been successfully used to produce ultrafine-grained (UFG) $\mathrm{Al}$ alloys with significantly enhanced mechanical strength and superplastic properties by comparison with metals subjected to conventional metal forming 5 . Among the various SPD methods, major attention has been devoted to equal-channel angular pressing $(\mathrm{ECAP})^{6}$, and especially to high-pressure torsion (HPT) ${ }^{7}$ as this procedure is more effective in fabricating UFG metals with grain sizes in the nanometre range $(<0.1 \mu \mathrm{m})$.

Al-Mg alloys processed by $\mathrm{ECAP}^{8-10}$ and $\mathrm{HPT}^{11,12}$ display superior mechanical strength compared with the coarse-grained material as a consequence of the intense strain hardening and grain refinement introduced during severe plastic deformation. The UFG Al-3Mg alloy has an average grain size of $\sim 0.27 \mu \mathrm{m}$ and a yield stress of $\sim 400 \mathrm{MPa}$ after processing by 8 passes of ECAP at room temperature using route $\mathrm{B}_{\mathrm{c}}^{8}$. In addition, even finer grain structures and further strengthening may be obtained after HPT processing, as recently reported for different Al-Mg alloys with $\% \mathrm{Mg}$ in weight of $\geq 1^{11,12}$. However, Al-Mg alloys usually exhibit early recrystallization and abnormal grain growth after SPD processing and subsequent heat treatment at relatively low temperatures ${ }^{11-14}$, thereby limiting their applications as structural components. Therefore, with the aim of improving the thermal stability of Al-Mg alloys, these metals may be alloyed with $\mathrm{Sc}$ additions because $\mathrm{Al}_{3} \mathrm{Sc}$ precipitates are effective in pinning the grain boundaries and retaining ultrafine grains even at high temperatures ${ }^{15-18}$.

Several investigations have demonstrated the outstanding mechanical properties and superplastic behaviour of Al-Mg-Sc alloys processed by $\mathrm{ECAP}^{19-22}$. Elongations of $>2000 \%{ }^{19,20}$ were attained in the ECAP-processed material tested in tension at $\mathrm{T} \geq 673 \mathrm{~K}$ at initial strain rates higher than $1.0 \times 10^{-2} \mathrm{~s}^{-1}$. Furthermore, it is interesting to note that even after annealing at $723 \mathrm{~K}$ for $1 \mathrm{~h}, \mathrm{Al}-\mathrm{Mg}$-Sc alloys processed by ECAP at different temperatures remain with grain structures with an average size of $<3 \mu \mathrm{m}^{15,18}$.

There are numerous studies showing that processing Al$\mathrm{Mg}-\mathrm{Sc}$ alloys by HPT leads to additional grain refinement and improved strength by comparison with the ECAP-processed meta $^{23-27}$. Conversely, it was revealed in a recent investigation ${ }^{28}$ that, although excellent low temperature superplasticity is achieved in the $\mathrm{Al}-3 \mathrm{Mg}-0.2 \mathrm{Sc}$ alloy processed by 10 turns of HPT, the elongations to failure after tensile testing at $\mathrm{T} \geq$ $623 \mathrm{~K}$ are notable inferior by comparing with the material processed by ECAP. Therefore, more information is needed to fully assess the microstructural evolution of the HPTprocessed alloy when exposed to elevated temperatures. Accordingly, the present study aims to evaluate the thermal stability of the Al-3Mg-0.2Sc alloy subjected to 10 turns of HPT processing by examining the mechanical properties and microstructural changes in this UFG alloy after annealing at temperatures up to $773 \mathrm{~K}$ for $1 \mathrm{~h}$. 


\section{Experimental Material and Procedures}

An Al-3\% Mg-0.2\% Sc (in wt. \%) alloy was supplied by China Rare Metal Material Corporation (Jiangxi Province, China) in the form of forged rods with $130 \mathrm{~mm}$ length and a diameter of $10 \mathrm{~mm}$. These rods were solution treated at $880 \pm 2 \mathrm{~K}$ for $1 \mathrm{~h}$ and then quenched in water. Discs with a thickness of $\sim 1 \mathrm{~mm}$ were cut from the heat treated metal and then were ground to a final thickness of $\sim 0.8 \mathrm{~mm}$.

Afterwards, the Al alloy was subjected to 10 turns of quasi-constrained HPT processing ${ }^{29-30}$ at an initial temperature of $\sim 300 \mathrm{~K}$. Initially, in the compression stage of HPT processing ${ }^{31}$, the discs were placed in a shallow central depression in the lower anvil and an axial load was applied at the surface of the samples in order to provide a nominal pressure of $6.0 \mathrm{GPa}$. The axial load was maintained constant and the lower anvil was rotated for 10 turns at a constant rate of $1 \mathrm{rpm}$ imposing high torsional straining within the material.

Following HPT processing, discs were annealed at temperatures from 423 to $773 \mathrm{~K}$ for $1 \mathrm{~h}$ and cooled in air. Thereafter, both the HPT-processed material and the annealed samples were ground and polished to a mirror-like quality and hardness measurements were taken at the middle-section of the discs following the same procedure described in earlier studies $^{27,32}$. The values of the Vickers microhardness were recorded using an FM300 microhardness tester equipped with a Vickers indenter under a load of $200 \mathrm{gf}$ and a dwell time of $15 \mathrm{~s}$. Hardness values were evaluated along the diameters of the discs at positions separated by $0.3 \mathrm{~mm}$ such that the microhardness in each position was calculated as the average of the measurements taken from four indentations separated by a distance of $0.15 \mathrm{~mm}$. In addition, the areaweighted average microhardness of the Al-3Mg-0.2Sc alloy was estimated using the hardness values recorded along the diameters of the discs as the measurements taken at increasing distance from the centre of the disc are associated with larger surface areas.

The microstructure of the HPT-processed material was examined by scanning electron microscopy (SEM) and orientation imaging microscopy (OIM) through electron backscattered diffraction (EBSD). Samples were ground, polished using $1 \mu \mathrm{m}$ diamond paste and $0.06 \mu \mathrm{m}$ silica colloidal and then etched using an aqueous solution of $5 \% \mathrm{HBF}_{4}$.

The grain structures of the Al-Mg-Sc alloy were observed using a JSM6500F thermal field emission SEM and the average grain size, $d$, was estimated using the linear intercept method. EBSD patterns with information about the local crystal orientation were collected on a regular grid using step sizes as small as $0.07 \mu \mathrm{m}$ and these were ultimately used to generate orientation maps for the HPT-processed metal annealed at $\mathrm{T} \geq 573 \mathrm{~K}$. A cleaning procedure, including grain dilatation, was performed on each of these maps, henceforth denoted OIM images, such that the total number of modified points was $<20 \%$ for all points measured. Low-angle grain boundaries (LAGBs) were defined as having misorientation differences between adjacent points from $2^{\circ}$ to $15^{\circ}$ and high-angle grain boundaries (HAGBs) had misorientations $>15^{\circ}$. The grain structures with HAGBs were coloured as a function of the grain sizes in each OIM image using a rainbow spectrum.

\section{Experimental Results}

The variation of Vickers microhardness along the diameters of the Al-Mg-Sc discs processed by HPT and further annealed is depicted in Figure 1, where the hardness measurements of the HPT-processed sample are denoted by open circles. The solution treated material exhibits a uniform microhardness distribution with hardness values of $\sim 58 \mathrm{Hv}$. Nevertheless, it is clearly seen that processing through 10 turns of HPT at ambient temperature leads to an intense hardening in this $\mathrm{Al}$ alloy, especially in the outer periphery of the disc in which hardness values $>200 \mathrm{Hv}$ were detected as in earlier investigations ${ }^{27}$. In addition, it is apparent that the microhardness distribution remains inhomogeneous after HPT processing and lower hardness values $(\sim 120 \mathrm{Hv})$ are observed in the centre of the disc.

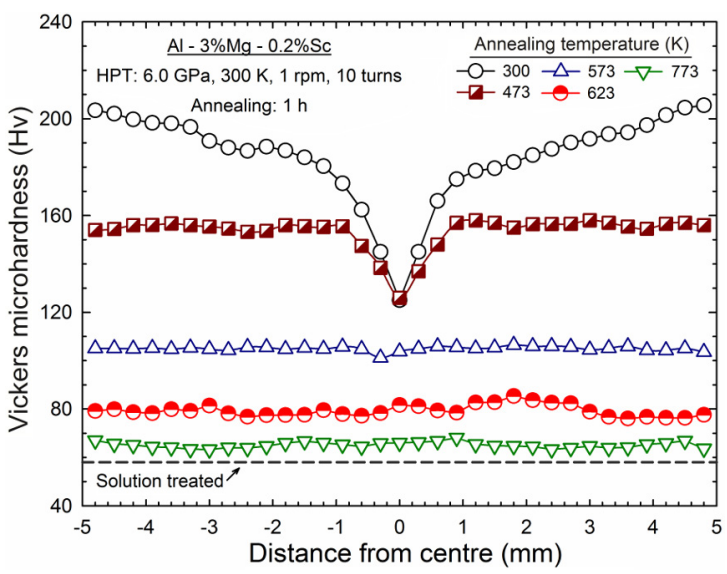

Figure 1. Variation of the average microhardness recorded at the middle-section position with distance from the centre of the $\mathrm{Al}-3 \mathrm{Mg}-0.2 \mathrm{Sc}$ discs after HPT processing at $300 \mathrm{~K}$ and further annealing.

It is readily noted from Figure 1 that after annealing at $473 \mathrm{~K}$ there is a substantial decrease in the microhardness of the HPT-processed material and the hardness distribution becomes fairly homogeneous, except at the central region of the sample wherein the hardness measurements are similar to those observed immediately after HPT processing. Additionally, annealing at $\mathrm{T} \geq 573 \mathrm{~K}$ results in a further reduction of the Vickers microhardness as well as a more uniform microhardness distribution in the HPT-processed discs. Conversely, local hardness variations of the order of $\sim 10 \mathrm{Hv}$ are evident in the middle-section of the Al alloy annealed at $623 \mathrm{~K}$ for $1 \mathrm{~h}$. 
In order to provide information about the softening kinetics in $\mathrm{Al}-\mathrm{Mg}-\mathrm{Sc}$ alloys exposed to elevated temperatures, Figure 2 shows the variation of the area-weighted average microhardness with the annealing temperature for $\mathrm{Al}-3 \mathrm{Mg}$ $0.2 \mathrm{Sc}$ discs processed by HPT and further annealed for 1 $\mathrm{h}$. The results reveal that the $\mathrm{Al}$ alloy exhibits an average microhardness of $\sim 190 \mathrm{Hv}$ after 10 turns of HPT and subsequent annealing at $\mathrm{T} \leq 423 \mathrm{~K}$. However, the results show that annealing in the temperature range from 473 to $623 \mathrm{~K}$ leads to a substantial reduction in the hardness values of the material previously processed by HPT. In addition, it is also apparent in Figure 2 that the Vickers microhardness continues to decrease but at a lower rate after annealing at $\mathrm{T} \geq 673 \mathrm{~K}$.

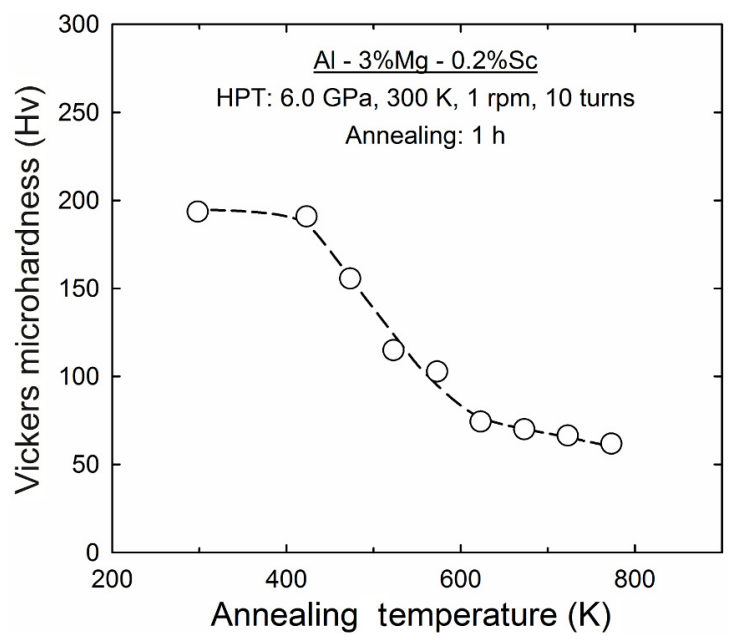

Figure 2. Average microhardness as a function of annealing temperature for the Al-3Mg-0.2Sc alloy subjected to 10 turns of HPT processing at $300 \mathrm{~K}$ and further annealed for $1 \mathrm{~h}$ at temperatures from 423 to $773 \mathrm{~K}$.

The grain boundaries of the Al-3Mg-0.2Sc alloy become evident after etching using an aqueous solution of $5 \% \mathrm{HBF}_{4}$. Accordingly, SEM images were obtained for the material processed by HPT as well as for the annealed discs and these images were used to estimate the grain size in each experimental condition with the aim of visualizing the variation of the grain size as a function of the annealing temperature for this $\mathrm{Al}$ alloy as shown in Figure 3.

The microstructure of the unprocessed Al-Mg-Sc alloy was fairly homogeneous and had an average grain size of $\sim 300 \mu \mathrm{m}^{27}$. Processing through 10 turns of HPT produced significant grain refinement in this $\mathrm{Al}$ alloy such that $d \approx$ $0.14 \mu \mathrm{m}$ as measured using SEM images taken at $\sim 3 \mathrm{~mm}$ from the centre of the disc. This refinement is consistent with other reports that used TEM images for estimating the grain size after HPT processing ${ }^{23-25}$. As depicted in Figure 3, there is no relevant increase in the size of the grain structures after annealing at $T \leq 473 \mathrm{~K}$. However, the grain sizes grow rapidly for $\mathrm{T} \geq 523 \mathrm{~K}$ such that $\mathrm{d}>1 \mu \mathrm{m}$ after annealing at

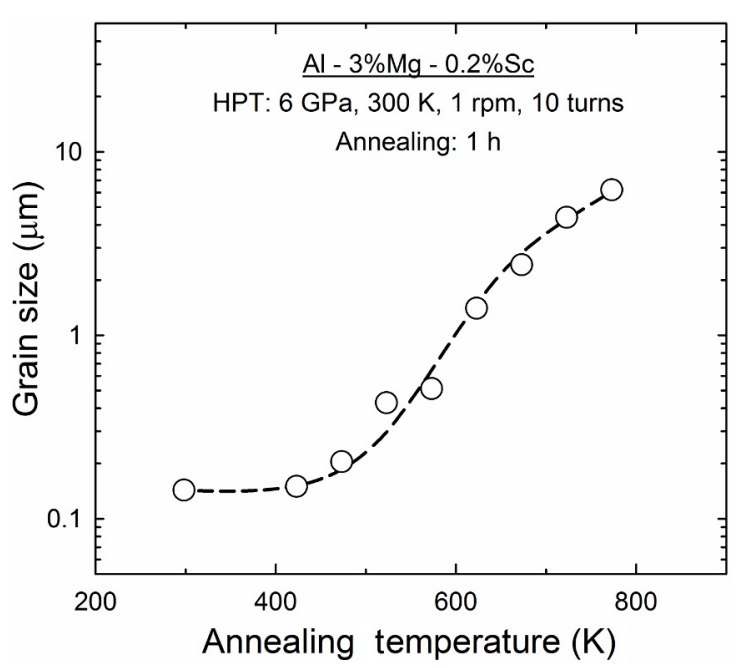

Figure 3. Grain size as a function of annealing temperature for the Al-3Mg- $0.2 \mathrm{Sc}$ alloy subjected to 10 turns of HPT processing at 300 $\mathrm{K}$ and further annealed for $1 \mathrm{~h}$ at temperatures from 423 to $773 \mathrm{~K}$.

$623 \mathrm{~K}$ and the average grain size is $\sim 6.2 \mu \mathrm{m}$ for the material heat treated at $773 \mathrm{~K}$ for $1 \mathrm{~h}$.

Figure 4 shows typical OIM images of the $\mathrm{Al}-3 \mathrm{Mg}-0.2 \mathrm{Sc}$ alloy processed by HPT at $300 \mathrm{~K}$ and further annealed at (a) 573, (b) 623 and (c) $773 \mathrm{~K}$. In addition, the grains were coloured using a rainbow spectrum such that small structures with HAGBs are blue and larger grains have shades of red. It is readily apparent from Figure 4 (a) that the UFG material annealed at $573 \mathrm{~K}$ has a uniform distribution of submicrometre grains with an average size of $\sim 0.5 \mu \mathrm{m}$ even after heat treatment for $1 \mathrm{~h}$. Furthermore, substructures with LAGBs are seldom observed within the grains with HAGBs.

Conversely, inspection of Figure 4 (b) reveals that there is an abnormal grain growth in the microstructure of the $\mathrm{Al}$ alloy annealed at $623 \mathrm{~K}$. The grain size in the grains coloured in blue is $\sim 1 \mu \mathrm{m}$ whereas more than $70 \%$ of the area fraction of the analysed image corresponds to large grains with $d>10 \mu \mathrm{m}$ containing a notable fraction of LAGBs in their interior. After annealing at $\mathrm{T}>673 \mathrm{~K}$, the fraction of coarse grains further increases as well as the grain sizes and the microstructural homogeneity and subgrains are clearly seen in Figure 4 (c) for the HPT-processed material annealed at $773 \mathrm{~K}$.

\section{Discussion}

The plots depicted in Figures 2 and 3 reveal that HPT processing leads to a significant hardening and grain refinement in Al-Mg alloys with $\mathrm{Sc}$ additions such that the Al-3Mg-0.2Sc alloy exhibits hardness values of $\sim 200 \mathrm{Hv}$ and an average grain size of $\sim 0.14 \mu \mathrm{m}$ after 10 turns of HPT at $300 \mathrm{~K}$. Nevertheless, the grain structures of this material become unstable and there is major grain coarsening after $1 \mathrm{~h}$ annealing at $\mathrm{T}>573 \mathrm{~K}$. 


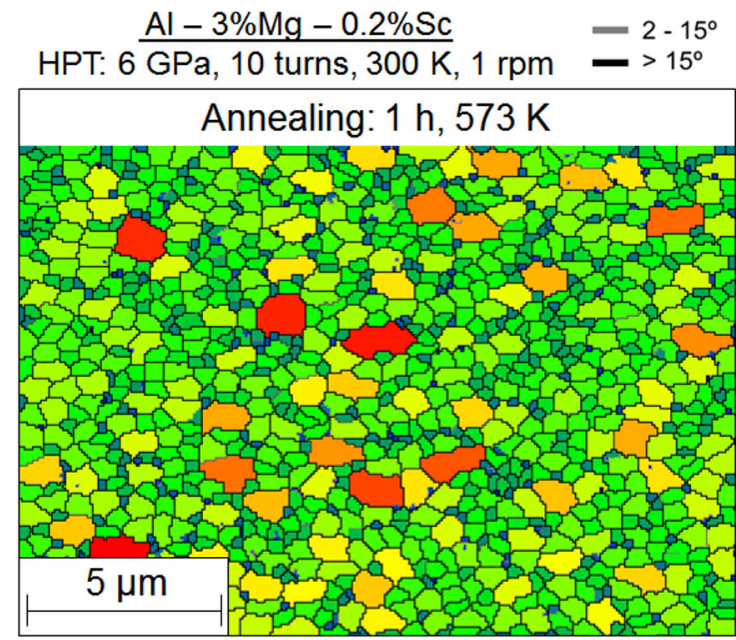

(a)

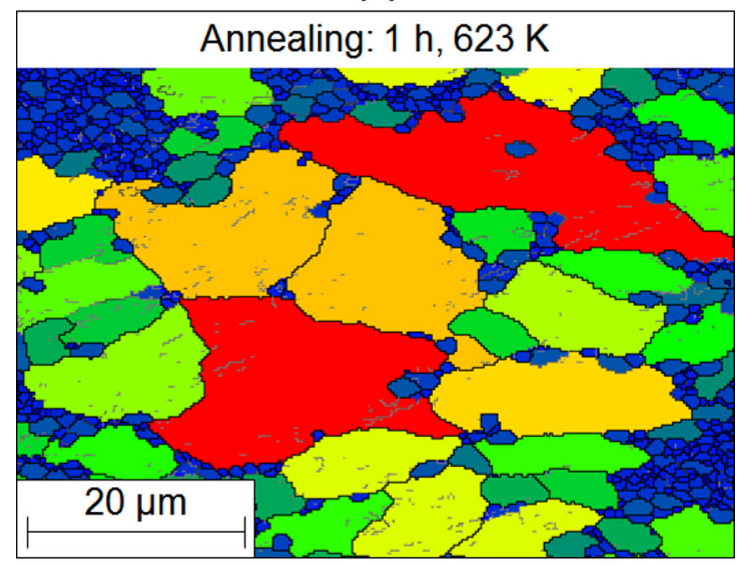

(b)

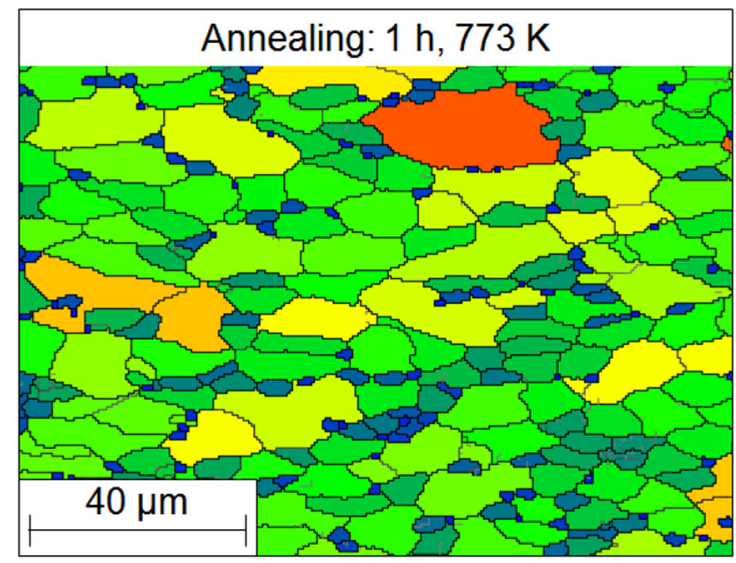

(c)

Figure 4. Grain size coloured images of the grain structures of the $\mathrm{Al}-3 \mathrm{Mg}-0.2 \mathrm{Sc}$ alloy processed by HPT at $300 \mathrm{~K}$ and further annealed for $1 \mathrm{~h}$ at (a) 573, (b) 623 and (c) $773 \mathrm{~K}$.

The microhardness distribution is reasonably uniform along the diameter of the HPT-processed metal after annealing at $573 \mathrm{~K}$ for $1 \mathrm{~h}$. Accordingly, Figure 4 (a) shows that a homogeneous microstructure develops in this material at the same annealing conditions. However, it is apparent in Figures 4 (b) and (c) that there is abnormal grain growth in the UFG alloy after annealing at $\mathrm{T} \geq 623 \mathrm{~K}$ as noted by its bi-modal grain distribution which also confirms the local hardness fluctuations observed in Figure 1.

An early investigation on the precipitation kinetics of a solution treated $\mathrm{Al}-0.2 \% \mathrm{Sc}$ alloy ${ }^{33}$ revealed that the nanosized $\mathrm{Al}_{3} \mathrm{Sc}$ precipitates are uniformly distributed within the microstructure of the Al-Sc alloy after heat treatment at temperatures below $623 \mathrm{~K}$, whereas aging at $\mathrm{T} \geq 643 \mathrm{~K}$ leads to an inhomogeneous distribution of dispersoids which start precipitating after aging times of the order of a few minutes. In the current study, discontinuous grain growth is clearly evident in the HPT-processed Al-3Mg-0.2Sc alloy after annealing for $1 \mathrm{~h}$ at 623 and $673 \mathrm{~K}$. Accordingly, as these temperatures are equivalent to the transition temperature between continuous and discontinuous precipitation of $\mathrm{Al}_{3} \mathrm{Sc}$ dispersoids in Al-Sc alloys, it is readily apparent that the formation of a bi-modal grain structure in the Al-3Mg$0.2 \mathrm{Sc}$ alloy is directly associated with the occurrence of discontinuous precipitation in the HPT-processed material during annealing. Furthermore, the continuous precipitation of $\mathrm{Al}_{3} \mathrm{Sc}$ dispersoids at $\mathrm{T} \leq 573 \mathrm{~K}$ inhibits the occurrence of abnormal grain growth at low homologous temperatures as observed for pure nickel after processing by 10 turns of $\mathrm{HPT}$ at $300 \mathrm{~K}$ and further annealing at $448 \mathrm{~K}^{34}$.

The formation of a duplex structure in UFG materials after annealing was also reported for an Al-3Mg alloy processed by ECAP ${ }^{14}$ and ECAP + cold rolling ${ }^{13}$. Nevertheless, recrystallization starts at lower temperatures $(\sim 500 \mathrm{~K})$ by comparison with the Al-3Mg-0.2Sc alloy processed by HPT at room temperature. The $\mathrm{Al}-3 \mathrm{Mg}$ alloy has an average grain size of $\sim 0.25 \mu \mathrm{m}$ after 8 passes of ECAP using a die with a channel angle of $\sim 120^{\circ}$. Following annealing at $523 \mathrm{~K}$ for $1 \mathrm{~h}$, the same material depicts a bi-modal grain distribution composed of fine grains with an average size of $\sim 0.35 \mu \mathrm{m}$ and coarse structures with $d \approx 5 \mu \mathrm{m}^{14}$. Therefore, the exceptional effectiveness of the $\mathrm{Al}_{3} \mathrm{Sc}$ dispersoids in delaying recrystallization in Al-Mg alloys is confirmed in this investigation, as the $\mathrm{Al}-3 \mathrm{Mg}-0.2 \mathrm{Sc}$ alloy processed by HPT exhibits smaller average grain sizes after annealing at identical conditions and there is no evidence of abnormal grain growth for $\mathrm{T}<623 \mathrm{~K}$.

It interesting to note that the $\mathrm{Al}-3 \mathrm{Mg}$ alloy processed by ECAP + rolling is fully recrystallized after annealing at $\mathrm{T} \geq 563 \mathrm{~K}^{13}$, however the structures with HAGBs continue growing with increasing annealing temperatures and their average sizes exceed $20 \mu \mathrm{m}$ after annealing at $\mathrm{T}>600 \mathrm{~K}$. By contrast, the HPT-processed Al-Mg-Sc alloy has an average grain size of $\sim 6.2 \mu \mathrm{m}$ even after annealing at $773 \mathrm{~K}$ and there are few remaining fine structures as apparent in Figure 4 (c).

The mechanical properties and microstructural evolution of Al-Mg alloys processed by HPT was examined in detail in recent reports ${ }^{11,12}$. It was revealed that the hardness in 
the $\mathrm{Al}-1 \mathrm{Mg}$ alloy saturates at $\sim 110 \mathrm{Hv}$ already after 3 turns of $\mathrm{HPT}^{11}$ whilst the Al-3Mg alloy only reaches a uniform microhardness distribution after processing for 10 turns and with an average Vickers microhardness $\sim 180 \mathrm{Hv}^{12}$. Additionally, the grains sizes in these materials after 10 turns of HPT are $\sim 230$ and $\sim 180-190 \mathrm{~nm}$ for the Al-1Mg and the $\mathrm{Al}-3 \mathrm{Mg}$ alloy, respectively. The current investigation demonstrates that the $\mathrm{Al}-3 \mathrm{Mg}-0.2 \mathrm{Sc}$ alloy continues having an inhomogeneous microhardness distribution even after 10 turns of HPT processing and further grain refinement is achieved by comparison with these Al-Mg alloys.

Similarly to the Al-3Mg- $0.2 \mathrm{Sc}$ alloy processed by HPT, grain coarsening was also reported in Al-Mg alloys after annealing for times varying from $10 \mathrm{~min}^{11}$ to $1 \mathrm{~h}^{12,35}$. Nevertheless, the grain sizes obtained after heat treatment are considerably larger for the $\mathrm{Al}-3 \mathrm{Mg}$ alloy such that HAGBs structures with an average grain size higher than $\sim 30 \mu \mathrm{m}$ are identified in the HPT-processed material ${ }^{12,35}$. Furthermore, the Vickers microhardness in the Al-3Mg alloy processed through 10 turns of HPT is $\sim 50 \mathrm{Hv}$ after subsequent annealing at $673 \mathrm{~K}$ for $1 \mathrm{~h}^{12}$ which is inferior to the average hardness of the HPT-processed $\mathrm{Al}-3 \mathrm{Mg}-0.2 \mathrm{Sc}$ alloy annealed at equivalent conditions $(\sim 78 \mathrm{Hv})$.

The grain boundary strengthening at low deformation temperatures may be expressed in terms of the Hall-Petch relationship considering the Vickers microhardness, $H$, and the average grain size, $d$, as follows ${ }^{36}$ :

$$
H=H_{0}+k_{H} d^{-1 / 2}
$$

where $H_{0}$ and $k_{H}$ are material constants.

There have been numerous exploratory studies discussing the validity of the Hall-Petch relationship for Al-Mg and Al-Mg-Sc alloys processed by ECAP and HPT ${ }^{12,18,22,26,35,36}$. In order to verify if this relationship remains accurate for Al-Mg-Sc alloys, the Vickers microhardness is plotted as a function of $d^{-1 / 2}$ for the $\mathrm{Al}-3 \mathrm{Mg}^{12,35}$ and the $\mathrm{Al}-3 \mathrm{Mg}-0.2 \mathrm{Sc}$ alloy after HPT processing at ambient temperature and after HPT followed by annealing for $1 \mathrm{~h}$ at temperatures ranging from 423 to $773 \mathrm{~K}$, as depicted in Figure 5.

It is noted from Figure 5 that there is a linear relationship between $H$ and $d^{-1 / 2}$ for the Al-3Mg-0.2Sc alloy processed by HPT at room temperature regardless of the annealing conditions. In addition, both the experimental datum points referring to the $\mathrm{Al}-3 \mathrm{Mg}-0.2 \mathrm{Sc}$ alloy and the data plotted for the HPT-processed Al-3Mg alloy corresponding to $d^{-1 / 2}<$ $\sim 2500 \mathrm{~m}^{-1 / 2}$ lie close to a single line with $H_{0}=31 \mathrm{Hv}$ and $k_{H} \approx 0.06 \mathrm{Hv} \mathrm{m}^{-1 / 2}$.

Figure 5 also reveals an apparent breakdown in the Hall-Petch relationship in the Al-3Mg alloy for $d<\sim 0.25$ $\mu \mathrm{m}$ whereas the Hall-Petch relationship remains valid for the Al-3Mg-0.2Sc alloy in the entire range of grain sizes evaluated in this and other studies ${ }^{22}$. The apparent absence of saturation in the hardness values of the $\mathrm{Al}-3 \mathrm{Mg}-0.2 \mathrm{Sc}$

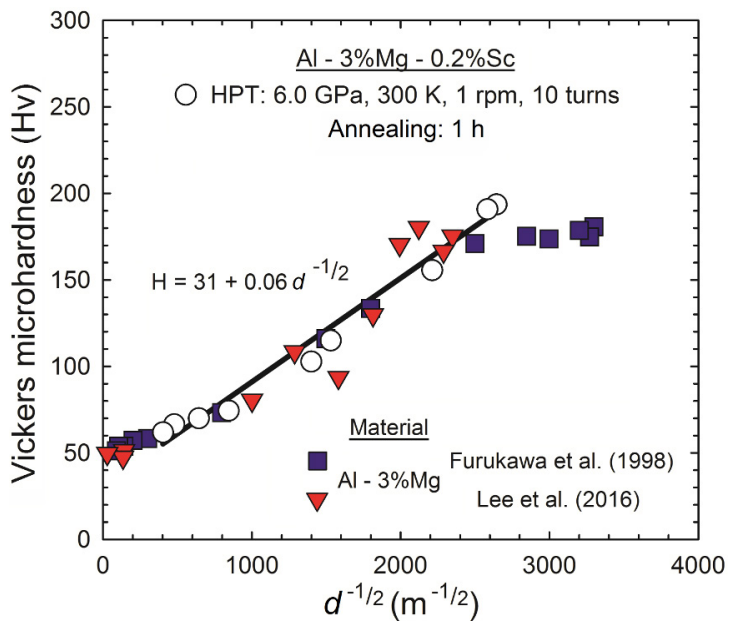

Figure 5. Plot of Vickers microhardness as a function of $d^{-1 / 2}$ for the $\mathrm{Al}-3 \mathrm{Mg}^{12,35}$ and the $\mathrm{Al}-3 \mathrm{Mg}-0.2 \mathrm{Sc}$ alloy after HPT processing at ambient temperature and after HPT followed by annealing for 1 $\mathrm{h}$ at temperatures ranging from 423 to $773 \mathrm{~K}$.

alloy after 10 turns of HPT as well as the continuing linearity between $H$ and $d^{-1 / 2}$ indicate that the UFG metal with Sc additions deforms primarily by intragranular dislocation glide at ambient temperature. There is experimental evidence of deformation-induced segregation of $\mathrm{Mg}$ at grain boundaries and triple junctions in $\mathrm{Al}-\mathrm{Mg}-\mathrm{Sc}$ alloys during SPD processing $^{22,26}$. Therefore, as these segregations are effective in suppressing the emission of extrinsic dislocations, they permit the action of intragranular slip as the most favourable deformation mechanism in this $\mathrm{Al}$ alloy at low homologous temperatures. Nevertheless, it is important to note that $\mathrm{Mg}$ segregation is not observed in the Al-3Mg alloy after highpressure torsion which underwent instead dissolution of $\mathrm{Mg}$ atoms in solid solution during processing ${ }^{12}$.

Severe plastic deformation through HPT processing leads to further strain hardening and grain refinement in the Al$3 \mathrm{Mg}-0.2 \mathrm{Sc}$ alloy ${ }^{23-27}$ compared with the same alloy processed by ECAP ${ }^{19-22}$. By contrast, the present work demonstrates that the material processed by HPT displays a more significant grain growth after post-SPD annealing by comparison with different Al-Mg-Sc alloys processed by ECAP and annealed at $\mathrm{T}>623 \mathrm{~K}^{15,18}$. The reasons for this apparent dichotomy may be assessed by considering the stored strain energy in the work-pieces after SPD processing. Even considering the temperature rise of the $\mathrm{Al}-3 \mathrm{Mg}-0.2 \mathrm{Sc}$ sample during HPT processing estimated as $\sim 30 \mathrm{~K}$ using an empirical relationship ${ }^{37,38}$, the density of microstructural defects in the material processed through 10 turns of HPT processing is notable higher than in the $\mathrm{Al}$ alloy processed by ECAP. Therefore, as the strain energy stored in the form of internal defects provides the driving force for recrystallization, this phenomenon starts at lower annealing temperatures in the HPT-processed alloy. 
A maximum elongation of $\sim 800 \%$ was reported for the Al-3Mg-0.2Sc alloy processed by 10 turns of HPT and tested in tension at $1.4 \times 10^{-2} \mathrm{~s}^{-1}$ at $573 \mathrm{~K}^{28}$. Conversely, the elongations attained in this material after testing at an identical strain rate at $\mathrm{T} \geq 623 \mathrm{~K}$ are $<470 \%$. These results are consistent with the grain size distributions presented in this study. Although, the Al-3Mg-0.2Sc alloy processed through 10 turns of HPT exhibits a duplex microstructure with grain sizes exceeding $10 \mu \mathrm{m}$ after annealing at 623 $\mathrm{K}$, the grain structures in this alloy remain ultrafine and homogeneously distributed after annealing at $\mathrm{T} \leq 573 \mathrm{~K}$. It is therefore concluded that the HPT-processed Al-3Mg- $0.2 \mathrm{Sc}$ alloy is a potential candidate for applications demanding light-weight materials fabricated through superplastic forming at low temperatures.

\section{Summary and Conclusions}

1. An Al-3\% Mg- $0.2 \% \mathrm{Sc}$ alloy was processed through 10 turns of HPT at room temperature to produce a grain size of $\sim 140 \mathrm{~nm}$ and an average microhardness of $\sim 190 \mathrm{Hv}$. Afterwards, annealing was conducted for $1 \mathrm{~h}$ at temperatures ranging from 423 to $773 \mathrm{~K}$.

2. There is no significant change in the microstructure of the HPT-processed metal after annealing at 423 $\mathrm{K}$. Nevertheless, there is a substantial reduction in the hardness values and a sharp increase in the grain sizes after annealing at $\mathrm{T} \geq 473 \mathrm{~K}$, although the grains remain ultrafine and have a reasonably uniform distribution after annealing at $573 \mathrm{~K}$.

3. Recrystallization occurs inhomogeneously leading to an abnormal grain growth and to a bi-modal distribution of grains after annealing at $\mathrm{T} \geq 623$ $\mathrm{K}$, and this becomes more uniform with increasing temperatures.

\section{Acknowledgements}

This work was supported by FAPEMIG under Collaborative Grant No. 515139108 between the University of Southampton and the Universidade Federal de Minas Gerais, by CAPES in Brazil and by the European Research Council under ERC Grant Agreement No. 267464-SPDMETALS.

\section{References}

1. Filatov YA, Yelagin VI, Zakharov VV. New Al-Mg-Sc alloys. Materials Science and Engineering: A. 2000;280(1):97-101.

2. Miller WS, Zhuang L, Bottema J, Wittebrood AJ, De Smet P, Haszler A, et al. Recent development in aluminium alloys for the automotive industry. Materials Science and Engineering: A. $2000 ; 280(1): 37-49$

3. Valiev RZ, Islamgaliev RK, Alexandrov IV. Bulk nanostructured materials from severe plastic deformation. Progress in Materials Science. 2000;45(2):103-189.
4. Langdon TG. Twenty-five years of ultrafine-grained materials: Achieving exceptional properties through grain refinement. Acta Materialia. 2013;61(19):7035-7059.

5. Sabirov I, Murashkin MY, Valiev RZ. Nanostructured aluminium alloys produced by severe plastic deformation: New horizons in development. Materials Science and Engineering: A. 2013;560:1-24.

6. Valiev RZ, Langdon TG. Principles of equal-channel angular pressing as a processing tool for grain refinement. Progress in Materials Science. 2006;51(7):881-981.

7. Zhilyaev AP, Langdon TG. Using high-pressure torsion for metal processing: Fundamentals and applications. Progress in Materials Science. 2008;53(6):893-979.

8. Iwahashi Y, Horita Z, Nemoto M, Langdon TG. Factors influencing the equilibrium grain size in equal-channel angular pressing: Role of $\mathrm{Mg}$ additions to aluminum. Metallurgical and Materials Transactions A. 1998;29(10):2503-2510.

9. Gubicza J, Chinh NQ, Horita Z, Langdon TG. Effect of Mg addition on microstructure and mechanical properties of aluminium. Materials Science and Engineering: A. 2004;387389:55-59.

10. Chen YJ, Chai YC, Roven HJ, Gireesh SS, Yu YD, Hjelen J. Microstructure and mechanical properties of Al-xMg alloys processed by room temperature ECAP. Materials Science and Engineering: A. 2012;545:139-147.

11. Andreau O, Gubicza J, Zhang NX, Huang Y, Jenei P, Langdon TG. Effect of short-term annealing on the microstructures and flow properties of an $\mathrm{Al}-1 \% \mathrm{Mg}$ alloy processed by high-pressure torsion. Materials Science and Engineering: A. 2014;615:231239.

12. Lee HJ, Han JK, Janakiraman S, Ahn B, Kawasaki M, Langdon TG. Significance of grain refinement on microstructure and mechanical properties of an $\mathrm{Al}-3 \% \mathrm{Mg}$ alloy processed by high-pressure torsion. Journal of Alloys and Compounds. 2016;686:998-1007.

13. Wang J, Iwahashi Y, Horita Z, Furukawa M, Nemoto M, Valiev $\mathrm{RZ}$, et al. An investigation of microstructural stability in an Al-Mg alloy with submicrometer grain size. Acta Materialia. 1996;44(7):2973-2982.

14. Morris DG, Muñoz-Morris MA. Microstructure of severely deformed Al-3Mg and its evolution during annealing. Acta Materialia. 2002;50(16):4047-4060

15. Lee S, Utsunomiya A, Akamatsu H, Neishi K, Furukawa M, Horita $\mathrm{Z}$, et al. Influence of scandium and zirconium on grain stability and superplastic ductilities in ultrafine-grained Al-Mg alloys. Acta Materialia. 2002;50(3):553-564.

16. Røyset J, Ryum N. Scandium in aluminium alloys. International Materials Reviews. 2005;50(1):19-44.

17. Dám K, Lejček P, Michalcová A. In situ TEM investigation of microstructural behavior of superplastic Al-Mg-Sc alloy. Materials Characterization. 2013;76:69-75.

18. Avtokratova E, Sitdikov O, Mukhametdinova O, Markushev M, Narayana Murty SVS, Prasad MJNV, et al. Microstructural evolution in Al-Mg-Sc-Zr alloy during severe plastic deformation and annealing. Journal of Alloys and Compounds. 2016;673:182194. 
19. Komura S, Horita Z, Furukawa M, Nemoto M, Langdon TG. An evaluation of the flow behavior during high strain rate superplasticity in an $\mathrm{Al}-\mathrm{Mg}-\mathrm{Sc}$ alloy. Metallurgical and Materials Transactions A. 2001;32(3):707-716.

20. Avtokratova E, Sitdikov O, Markushev M, Mulyukov R. Extraordinary high-strain rate superplasticity of severely deformed Al-Mg-Sc-Zr alloy. Materials Science and Engineering: $A$. 2012;538:386-390.

21. Zhemchuzhnikova D, Kaibyshev R. Mechanical Behavior of an Al-Mg-Mn-Sc alloy with an Ultrafine Grain Structure at Cryogenic Temperatures. Advanced Engineering Materials. 2015;17(12):1804-1811.

22. Pereira PHR, Wang YC, Huang Y, Langdon TG. Influence of grain size on the flow properties of an Al-Mg-Sc alloy over seven orders of magnitude of strain rate. Materials Science and Engineering: A. 2017;685:367-376.

23. Sakai G, Horita Z, Langdon TG. Grain refinement and superplasticity in an aluminum alloy processed by high-pressure torsion. Materials Science and Engineering: A. 2005;393(12):344-351.

24. Perevezentsev VN, Shcherban MY, Murashkin MY, Valiev RZ. High-strain-rate superplasticity of nanocrystalline aluminum alloy 1570. Technical Physics Letters. 2007;33(8):648-650.

25. Horita Z, Langdon TG. Achieving exceptional superplasticity in a bulk aluminum alloy processed by high-pressure torsion. Scripta Materialia. 2008;58(11):1029-1032.

26. Valiev RZ, Enikeev NA, Murashkin MY, Kazykhanov VU, Sauvage X. On the origin of the extremely high strength of ultrafine-grained $\mathrm{Al}$ alloys produced by severe plastic deformation. Scripta Materialia. 2010;63(9):949-952.

27. Pereira PHR, Huang Y, Langdon TG. Influence of initial heat treatment on the microhardness evolution of an Al-Mg-Sc alloy processed by high-pressure torsion. Materials Science Forum. 2017;879:1471-1476.

28. Pereira PHR, Huang Y, Langdon TG. Examining the mechanical properties and superplastic behaviour in an Al-Mg-Sc alloy after processing by HPT. Letters on Materials. 2015;5(3):294-300.
29. Figueiredo RB, Cetlin PR, Langdon TG. Using finite element modeling to examine the flow processes in quasi-constrained high-pressure torsion. Materials Science and Engineering: A. 2011;528(28):8198-8204.

30. Pereira PHR, Figueiredo RB, Cetlin PR, Langdon TG. Using finite element modeling to examine the flow process and temperature evolution in HPT under different constraining conditions. IOP Conference Series: Materials Science and Engineering. 2014;63(1):012041.

31. Pereira PHR, Figueiredo RB, Cetlin PR, Langdon TG. An examination of the elastic distortions of anvils in high-pressure torsion. Materials Science and Engineering: A. 2015;631:201208.

32. Kawasaki M, Langdon TG. The significance of strain reversals during processing by high-pressure torsion. Materials Science and Engineering: A. 2008;498(1-2):341-348.

33. Røyset J, Ryum N. Kinetics and mechanisms of precipitation in an Al-0.2 wt.\% Sc alloy. Materials Science and Engineering: A. 2005;396(1-2):409-422.

34. Ghosh P, Renk O, Pippan R. Microtexture analysis of restoration mechanisms during high pressure torsion of pure nickel. Materials Science and Engineering: A. 2017;684:101-109.

35. Furukawa M, Horita Z, Nemoto M, Valiev RZ, Langdon TG. Microhardness measurements and the Hall-Petch relationship in an Al-Mg alloy with submicrometre grain size. Acta Materialia. 1996;44(11):4619-4629.

36. Furukawa M, Horita Z, Nemoto M, Valiev RZ, Langdon TG. Factors influencing the flow and hardness of materials with ultrafine grain sizes. Philosophical Magazine A. 1998;78(1):203216 .

37. Figueiredo RB, Pereira PHR, Aguilar MTP, Cetlin PR, Langdon TG. Using finite element modeling to examine the temperature distribution in quasi-constrained high-pressure torsion. Acta Materialia. 2012;60(6-7):3190-3198.

38. Pereira PHR, Figueiredo RB, Huang Y, Cetlin PR, Langdon TG. Modeling the temperature rise in high-pressure torsion. Materials Science and Engineering: A. 2014;593:185-188. 